\title{
VENTRICULAR SEPTAL DEFECT AT AN UNUSUAL SITE WITH OTHER CONGENITAL ANOMALIES
}

\author{
BY \\ N. R. KONAR AND A. N. SEN GUPTA \\ From the Nilratan Sircar Medical College, Calcutta
}

Roger (1879) gave the first description of isolated ventricular septal defect. Cases are often detected during routine medical examinations of school children by the characteristic loud, harsh systolic murmur over the third or fourth left interspace close to the sternum, but others simulating this may have only innocent parasternal murmurs (Wood, 1950).

The usual site of the defect is near the base of the septum. In Abbott's series there were 50 patients with lesions at this site and only 5 with defects that were multiple or were situated elsewhere (Bauer and Astbury, 1944). Weiss (1927) had a case with a defect in the interventricular septum near the apex of the heart. Brown (1950) noted right axis deviation in his case where the defect was near the apex.

The present patient had peculiar clinical features due to the unusual site of the defect and had also congenital anomalies in other parts of the body.

An unmarried man, aged 35 years, was admitted under one of us (N.R.K.) with history of dyspnœa and cough for five months, and œdema of the legs for 15 days. The dyspnœa was at first on exertion only but later it became constant. He had no fever. Till the onset of dyspnœa he had good health and was of active habits. There was no significant past, family or personal history. The patient was of poor build and nutrition, and hair was very scanty over his face, axillæ, and pubes. There was moderate cyanosis but no clubbing of fingers. Pitting œedema was present over both feet, legs, and thighs.

He had bilateral branchial and pre-auricular fistulæ. There were no testes in the scrotal sacs. The chest was box shaped and the sternum was depressed.

The pulse was 90 a minute and regular. The blood pressure was $85 / 65 \mathrm{~mm}$. Hg. A feeble apical impulse was felt over the fifth left interspace in the midclavicular line. There was a systolic thrill in this area. A localized systolic murmur of moderate intensity was heard in the mitral area. The pulmonary second sound was accentuated and split, and a systolic murmur was also heard in this area. Crepitations were heard over both lung bases. The veins of the neck were full. The liver was enlarged three fingers' breadth below the costal margin and was firm and tender. The spleen was just palpable. There was a little fluid in the peritoneal cavity.

The hæmoglobin was $12.6 \mathrm{~g}$. per $100 \mathrm{ml}$. and the total white count and the differential count, and the blood sedimentation rate were normal. The Wasserman reaction was negative.

Radiological examination showed slight enlargement of the right ventricle and moderate enlargement of the left ventricle and pulmonary conus (Fig. 1). There was moderate pulmonary congestion but no hilar dance. The electrocardiograms showed sinus rhythm, right axis deviation, depressed S-T in II and III, biphasic T waves in II and III, and normal QRS complexes. The slow rate and S-T depressions were due to digitalis. On cardiac catheterization the right atrial pressure was $5 \mathrm{~mm}$. $\mathrm{Hg}$ and the oxygen saturation of its blood was 62 per cent. The catheter could not be passed to the left side of the heart.

He improved with rest, salt-poor diet, digitalis, and mercurial diuretics; the œdema and ascites disappeared and only a tinge of cyanosis was present but the liver was still enlarged.

He only remained well for two weeks after leaving hospital and then had to be re-admitted with recurrence of the same symptoms. There were in addition a diastolic thrill and a diastolic murmur of moderate intensity over the third left interspace close to the sternum. The venous pressure in 


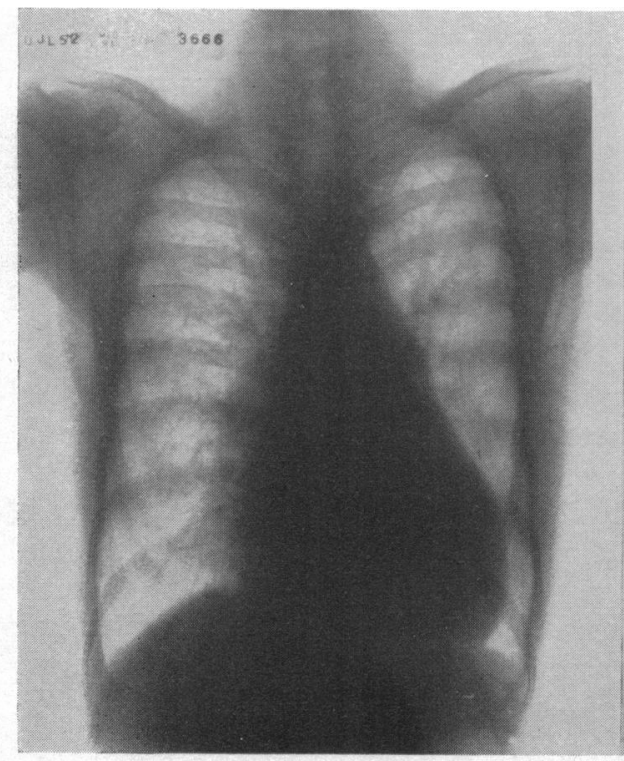

A

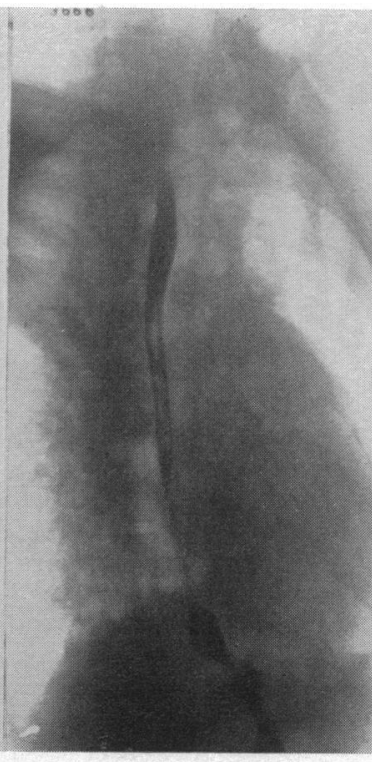

B

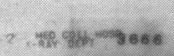

Fig. 1.-Teleradiogram of the heart. (A) in the antero-posterior position, (B) in the right anterior oblique, and (C) in the left anterior oblique position.

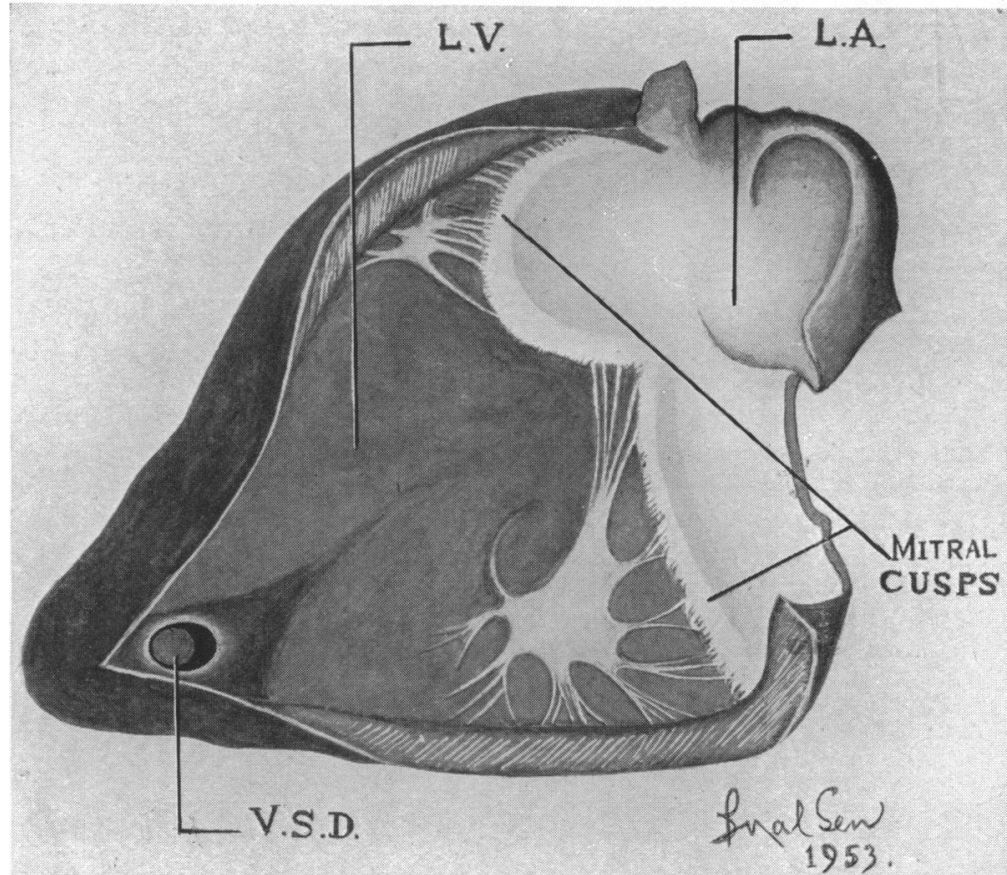

Fig. 2.-Drawing of the heart from the left ventricle showing the low ventricular septal defect. 
the median cubital vein was raised to $20 \mathrm{~cm}$. of blood and later to $32 \mathrm{~cm}$. The arm-to-tongue circulation time (decholine) was 32 seconds. In spite of treatment his condition gradually got worse; he became odematous and cyanotic and at times there were râles and rhonchi in both lungs with severe dyspnœa, presumably left ventricular failure. He died four months after his admission.

Post-mortem examination. There was œedema of the legs. There were two pre-auricular fistulæ, and the one on the right side could be traced deep into the right temporal bone. The right branchial fistula could be traced almost to the posterior wall of the pharynx.

The heart weighed $362 \mathrm{~g}$. The pericardial cavity contained $200 \mathrm{ml}$. of straw-coloured fluid. No abnormalities were seen in the atria or in the septum between them. The coronary sinus was wide enough to admit the tip of the little finger. The right ventricle was dilated and the thickness of its wall was $6 \mathrm{~mm}$. and that of the left ventricle $9 \mathrm{~mm}$. The interventricular septum showed a defect near the apex of the heart (Fig. 2): it was oval in shape and measured $10 \times 6 \mathrm{~cm}$. and was lined by endocardium. No abnormalities were seen in the endocardial surface of the right ventricle. The four valves were normal. The pulmonary artery was widely dilated.

Firm adhesions were present between the lungs and the chest wall on both sides, but the lungs were otherwise healthy. There were no arteriosclerotic changes in the pulmonary vessels. The peritoneal cavity contained about $300 \mathrm{ml}$. of straw-coloured fluid and there were plastic adhesions between coils of intestine. The liver was nutmeg in appearance. The spleen was congested and showed a small infarct. The right testis was in the right iliac fossa and the left at the brim of the pelvis: they were small in size and the cut surface showed degenerated tissue.

\section{Discussion}

The systolic thrill and murmur at the mitral area in this case are explained by the peculiar site of the ventricular septal defect. The diastolic thrill and murmur at the third left interspace close to the sternum which appeared during the later part of the disease were thought to be due to functional pulmonary incompetence. The patient developed congestive cardiac failure about a year before his death. The cyanosis in this case was most probably due to right heart failure: in the absence of the figures for the oxygen saturation of right ventricular blood it is difficult to say if there were any reversal of shunt.

\section{Summary}

A case of isolated ventricular septal defect situated close to the apex of the heart has been described. The defect produced a systolic thrill and a murmur at the mitral area. Cyanosis was a prominent feature, but was probably due to right heart failure.

The patient also had bilateral pre-auricular and branchial fistulæ and the testes did not descend to the scrotal sacs.

We are grateful to Dr. A. K. Dutta Gupta, Principal-cum-Superintendent, Nilratan Sircar Medical College and Hospitals for permission to report the case, to Professor S. N. De for the post-mortem reports, to Prof. H. L. Saha for the biochemical reports, and to Dr. B. Sen for the sketch.

\section{REFERENCES}

Bauer, D. de F., and Austbury, E. C. (1944). Amer. Heart J., 27, 688.

Brown, J. W. (1950). Congenital Heart Disease. Staples, London.

Roger, H. (1879). Bull. Acad. Roy. Med., 8, 1074.

Weiss, E. (1927). Arch. intern. Med., 39, 705.

Wood, P. (1950). Brit. Heart J., 12, 202. 